\title{
Agronegocios, pueblos indígenas y procesos migratorios rururbanos en la provincia de Salta, Argentina
}

\author{
Agribusiness, Indigenous Peoples and Rururban Migratory \\ Processes in the Province of Salta, Argentina
}

D0I: $10.22380 / 2539472 X .799$

\author{
Mónica Flores Klarik* \\ Universidad Nacional de Salta, Argentina
}

\begin{abstract}
RESUMEN
Este trabajo aborda los efectos de los agronegocios sobre la vida cotidiana de las comunidades wichí de la provincia de Salta, Argentina, enfocándose en los procesos de migración rural urbana a causa de los desmontes. Se parte del supuesto de que asistimos a un proceso de reconfiguración territorial y urbanización de la vida, producto del modelo neoextractivista, que genera una doble desvinculación de la población rural con respecto a la tierra y al trabajo, e inhabilita la reproducción cultural y la subsistencia de los pueblos indígenas. Estos cambios se analizan a partir de un estudio estadístico y desde un enfoque etnográfico se desvela la visión de las comunidades, así como las distintas formas de resistencias que llevan a cabo para defender su medio de vida.
\end{abstract}

\begin{abstract}
$\overline{\text { ABSTRACT }}$
This paper discusses agribusiness impact on Wichi people daily life in Salta, Argentina. Focusing on rural-urban migration and settlement due to tree clearing, the paper analyzes the process of territorial reconfiguration and urbanization of life as a result of the neo-extractive model. First, as a process that expels rural people from their land and forces them out of work. Second, as a process that disables indigenous peoples' cultural reproduction and subsistence. The work analyzes these changes from a statistical study and from an ethnographic approach we reveal the vision of the communities, as well as the different forms of resistance that they carry out in defense of their livelihoods.
\end{abstract}

Keywords: Agribusiness, indigenous people, extractivism, rurban migration.

Palabras claves: agronegocios, pueblos indígenas, extractivismo, migraciones rururbanas.

Doctora en Antropología de la Universidad de Buenos Aires. Profesora adjunta de la Universidad Nacional de Salta. moniflork@yahoo.com.ar / https://orcid.org/0000-0002-0067-2195 


\section{Introducción}

Me aferro a este lugar aunque se enojen conmigo. Si me quieren matar que me maten, ni aun así dejaré de estar aquí. Teresa Mendoza, Comunidad Wichí de Corralito, 2011

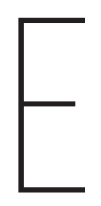

n Argentina, las demandas colectivas indígenas tienen como trasfondo conflictos territoriales que se han activado como parte del proceso de transnacionalización del capital, viabilizado a través de políticas neoliberales. Ante este proceso, que incluyó el despojo de medios de subsistencia y la pérdida de territorios, diferentes formas de lucha y movilización de las organizaciones indígenas han ido contestando e intentando frenar tales hechos. Estos conflictos tienen como denominador común la presión de las actividades extractivas — principalmente la minería y la producción agrícola-que impactan sobre áreas de territorio de ocupación indígena y sobre los recursos naturales que son cruciales para la reproducción de la vida de las comunidades ${ }^{1}$.

Este trabajo ${ }^{2}$ tiene como propósito contribuir al conocimiento de las nuevas configuraciones socioterritoriales vinculadas a las transformaciones económicas del denominado "modelo extractivista" (Giarraca y Teubal 2013, 19-21) y las demandas por derechos colectivos que plantean los pueblos indígenas ante el Estado. A fin de contribuir a consolidar una perspectiva general sobre este fenómeno, este estudio se enfoca en el departamento San Martín, provincia de Salta, uno de los sectores más afectados por los agronegocios, mostrando los procesos de expulsión de población rural y la relocalización en ámbitos urbanos de las comunidades indígenas del pueblo wichí.

Para examinar estos procesos, la primera parte del estudio se basa en el análisis de datos estadísticos de censos de población y de otras fuentes que muestran las cifras de deforestación en el Chaco salteño. En la segunda parte, se utilizan registros etnográficos propios y de otras investigaciones de tipo cualitativo, de las cuales se han tomado testimonios de las personas afectadas. El periodo

1 En Argentina se reconocen alrededor de 33 pueblos indígenas. La provincia de Salta cuenta con 12 pueblos: wichí, chorote, chulupí, tapiete, ava guaraní, chané, toba o qom, kolla, diaguita, tastil, lule e iogys.

2 Se enmarca en el Proyecto Ciunsa Tipo B 2406 "Estado, pueblos indígenas. Reconocimiento de derechos colectivos y nuevas configuraciones socioterritoriales en Salta" y "Territorialidad y poder. Conflictos, exclusión y resistencia en la construcción de la sociedad en Salta". ICSOHConicet-UNSA. CCT Salta. 
examinado corresponde a los años 2001-2015, momento de auge de la expansión de la frontera agropecuaria en el área mencionada ${ }^{3}$.

\section{Extractivismo y movilizaciones indígenas}

Son múltiples los casos de conflicto social en el norte argentino que dan cuenta de una agudización de la disputa por el acceso a la tierra y los recursos naturales vinculados a la implementación del modelo extractivo contemporáneo, en este caso, relacionado con el monocultivo de soja para exportación, proceso común en otros países latinoamericanos (Composto y Navarro 2014; Giarraca y Teubal 2013; Gudynas 2009; Rodríguez 2016; Svampa y Antonelli 2009). En el caso argentino, este es considerado como una segunda fase del modelo neoliberal concomitante al periodo de convertibilidad. Mientras que en la década de los noventa el modelo implicaba una desregulación de lo económico, el ajuste fiscal, la privatización de los servicios públicos e hidrocarburos y una apertura de las inversiones externas, en la etapa de posconvertibilidad, se pone en marcha a partir de la radicación de grandes empresas transnacionales, que alentaron actividades económicas para la exportación. Se promueve así la extracción de recursos no renovables, como la minería a cielo abierto, la construcción de megarrepresas, los proyectos de integración regional y los agrocombustibles, que ponen en el centro de disputa el territorio y el medio ambiente (Merlinky 2013; Svampa 2008) ${ }^{4}$.

3 Los extractos de entrevistas corresponden a mi investigación doctoral (Flores 2011). También incluyen investigaciones realizadas por Paolo Sanguinetti del Proyecto Ciunsa 1968, "Dinámica poblacional y territorio en el Umbral al Chaco. Estudio focalizado en el municipio Ballivián-dpto. San Martín, Salta", dirigido por Marcela Amalia Álvarez; y del Proyecto Ciunsa Tipo B 2406, "Estado, pueblos indígenas. Reconocimiento de derechos colectivos y nuevas configuraciones socioterritoriales en Salta", bajo mi dirección. Reúne asimismo información obtenida en el acompañamiento de demandas colectivas de comunidades indígenas wichí en los siguientes juicios: Caso "Comunidad El Traslado, Zopota y El Escrito c/ Estado Nacional S/ Acción de Amparo" (expte. n. ${ }^{\circ}$ 1271/06, tramitado ante el Juzgado Federal de Orán, Secretaría Civil 1, provincia de Salta, en el mes de junio del 2009); caso "Comunidad de San José-Chustaj Lhokwe y Comunidad de Cuchuy contra Estado Nacional y otros. S/ Amparo Colectivo" (Juzgado San Ramón de la Nueva Orán, exp. sin citar por estar en curso). Estos últimos incluyen trabajo de campo realizado en Ballivián y Tartagal con las licenciadas Marcela Amalia Álvarez y Norma Naharro. Otros testimonios fueron extraídos de material audiovisual elaborado por la fundación Acompañamiento Social de la Iglesia Anglicana del Norte Argentino (Asociana). Agradezco a la ingeniera Ana Álvarez por su colaboración.

4 La etapa de posconvertibilidad incluye el periodo kirchnerista (2002-2016) y la actual presidencia de Mauricio Macri, esta última de mayor liberalización económica y de ajuste en el plano social. 
Según Giarracca y Teubal (2013), los agronegocios en Argentina, en especial la expansión sojera, son parte de este nuevo modelo extractivo. Al igual que la minería, se vinculan con los intereses de grandes corporaciones, operan en grandes escalas de producción que arrinconan las formas productivas ya existentes y utilizan tecnologías de punta. Se localizan en territorios donde están los recursos naturales de los que dependen y desplazan masivamente a las poblaciones rurales. Se apropian de recursos no reproducibles, como el agua, la tierra fértil y la biodiversidad, que son esenciales para la vida de las comunidades. Se orientan a la exportación, con lo cual no resuelven necesidades internas de la región a la vez que generan conflictos (Giarracca y Teubal 2013, 21-23).

Estas nuevas configuraciones socioterritoriales activaron las luchas ancestrales por la tierra a través de diferentes movilizaciones indígenas y campesinas en defensa de los recursos naturales (Domínguez y Sabatino 2008; Galafassi 2008; Gordillo y Hirsch 2010), que produjeron una nueva cartografía de las resistencias. Mientras que en los noventa los conflictos con el Estado eran impulsados principalmente por la demanda de trabajo asalariado, luego del 2000 las movilizaciones han sido por recursos. Estas resistencias ponen en evidencia la contradicción entre las economías domésticas campesinas e indígenas con los modelos de desarrollo centrados en la concepción de la naturaleza como mercancía (Manzanal y Villarreal 2010; Merlinsky 2013; Svampa y Antonelli 2009).

El monocultivo de la soja comenzó en la zona de la pampa húmeda y posteriormente se extendió a los territorios del norte y del este del país. Implicó la deforestación a gran escala de áreas de bosque nativo y continuó creciendo a pesar de normativas ambientales que la prohíben (Adámoli, Ginzburg y Torrella 2011; Azcuy y Ortega 2010; Schmidt 2009; Slutsky 2005).

El Chaco salteño es una de las zonas del país donde se ha presentado una mayor cantidad de conflictos (Bidaseca 2014). Allí es notable cómo los grupos más vulnerados, pertenecientes a diferentes pueblos originarios, han revitalizado sus demandas hacia el Estado, amparados en las normativas constitucionales y la legislación internacional que reconocen derechos a las comunidades y pueblos indígenas (artículo 75, inciso 17 del Convenio 169 de la Organización Internacional del Trabajo [OIT]). Y hay un incremento de casos que se han canalizado judicialmente. Tales procesos se han potenciado dado que los territorios de ocupación indígena, generalmente ubicados en áreas de frontera o en espacios “marginales”, coinciden con las áreas de territorio incorporadas como productivas en las últimas décadas.

En términos teóricos, estos procesos pueden entenderse siguiendo el planteamiento de Harvey (2004) acerca de la noción de acumulación por desposesión, 
producto de la transnacionalización del capital y la reconfiguración de los espacios en términos de una contradicción entre lógicas territoriales distintas, favorecida por la conjugación de nuevos ordenamientos jurídicos (De Sousa Santos 1991). Tales reordenamientos espaciales y jurídicos son justificados desde la episteme del desarrollo como discurso hegemónico (Escobar 1995, 2005) que, en las prácticas, pone en tensión otras territorialidades y concepciones de la naturaleza, contribuyendo a la reproducción de las contradicciones materiales u objetivas de las desigualdades y relaciones de poder existentes en la sociedad.

Como proponen Composto y Navarro (2014), los procesos de desposesión son constitutivos de la lógica de acumulación de capital desde sus orígenes y de las políticas imperiales de expansión capitalista en las periferias - procesos que aún continúan vigentes y exacerbándose en sus antagonismos-. Tales reconfiguraciones han transformado bienes comunes naturales como la tierra, el agua y la biodiversidad en mercancías. El Estado es el garante principal del capital y asegura la concreción de estas prácticas mediante diferentes mecanismos que van desde la vía institucional (política, administrativa y jurídica) hasta la cooptación y represión de las movilizaciones sociales. Siguiendo a Zibechi (2014):

[...] el principal instrumento de la acumulación por desposesión es la violencia, y sus agentes son, indistintamente, poderes estatales, paraestatales y privados, que en muchos casos trabajan juntos pues comparten los mismos objetivos. Esa es la situación que en nuestro continente viven las poblaciones cercanas a las minas y los monocultivos. (78)

A lo largo de la historia de Latinoamérica, estas transformaciones han generado diversas formas de resistencia y luchas por la preservación de otras maneras de ser y estar en el mundo de pueblos indígenas y campesinos. En las últimas cuatro décadas, con la exacerbación de la contradicción capital-naturaleza (Composto y Navarro 2014), diferentes poblaciones se oponen a este avance y están resistiendo al extractivismo. De acuerdo con Zibechi (2014):

La novedad de esta nueva guerra es que los enemigos no son los ejércitos de otros estados, ni siquiera otros estados, sino la propia población, en particular, aquella parte de la humanidad que vive en la zona del no-ser. En suma, se trata de: acabar con los pueblos que sobran, desertizar territorios y luego reconectarlos al mercado mundial. Los modos de eliminar a los pueblos no implican necesariamente la muerte física, aunque esta va sucediendo lentamente mediante la expansión de la desnutrición crónica y las viejas y nuevas enfermedades como el cáncer, que afecta a millones de quienes están expuestos a los químicos de los monocultivos y de la minería [...] Se trata de procesos a partir de los cuales las comunidades luchan palmo a palmo por el territorio, organizándose para no dejar ingresar a las multinacionales o para expulsar- 
las, convierten los territorios en barricadas y los cuerpos en trincheras, a falta de leyes, de estados y autoridades que los amparen. Es el modo como siempre han luchado los de más abajo: poniendo el cuerpo, arriesgando la vida, las familias, los hijos. No tienen otro camino, porque viven en la zona del no-ser, en la que su humanidad no es reconocida. $(78-84)$

\section{Desmontes y procesos migratorios rurubanos del Chaco salteño}

En este apartado realizaremos una aproximación cuantitativa a los procesos de desmonte ${ }^{5}$ y despoblamiento rural en el Chaco salteño que ocupa los departamentos de Anta, San Martín, Orán y Rivadavia. El análisis se realizará teniendo en cuenta los censos poblacionales 2001-2010 y otros estudios que dan cuenta del avance de la frontera agropecuaria. Según Leake, López y Leake (2016):

Los bosques tropicales secos del Chaco argentino y paraguayo, en particular, han sufrido las tasas más altas de deforestación con un incremento en la última década [...] De hecho, el Fondo Mundial para la Naturaleza (WWF) incluye el Gran Chaco entre los once frentes de deforestación masiva a nivel mundial. (11)

En el Chaco semiárido argentino se estima que hasta el año 2015 fueron desmontadas más de 12 millones de hectáreas de bosque nativo ${ }^{6}$. De esa superficie,

5 Por desmonte se entiende la práctica de la deforestación de grandes superficies de bosque nativo para llevar a cabo la agricultura a gran escala. Esta práctica se inicia con la derriba de la cobertura forestal con maquinaria y luego el "destronque" que se realiza de manera manual. Las empresas agrícolas son de capitales transnacionales con participación de empresarios provinciales y nacionales, muchos de los cuales ocupan alguna función pública.

6 El Chaco salteño corresponde a una porción occidental del Gran Chaco sudamericano que incluye territorios de Bolivia, Paraguay y Argentina. El Chaco argentino se ubica al norte del país (en las provincias de Salta, Chaco, Formosa y Santiago del Estero), tiene características de monte y clima semidesértico. En Argentina la expansión de la frontera agrícola se extendió desde la Pampa húmeda situada en el centro del país hacia el noroeste. La expansión del monocultivo de la soja, por su valor en el mercado y la especulación que generó, produjo el corrimiento de la frontera agrícola a zonas cubiertas de bosque nativo, en donde se requiere la deforestación a gran escala para la puesta en producción. Una de las principales consecuencias de esta práctica es el impacto ambiental, ya que implica la desertificación del suelo, además de otros efectos que se generan por la pérdida irreversible de especies vegetales y animales. La salud de las personas también se vulnera debido a que el cultivo se acompaña de agrotóxicos. Los pobladores más afectados por la pérdida de bosque son principalmente las comunidades indígenas y familias campesinas que no tienen títulos de 
aproximadamente el 18\% corresponde a la provincia de Salta (Leake, López y Leake 2016, 11).

En el Chaco salteño, de los 2,2 millones de hectáreas de bosque nativo desmontadas, el $45 \%$ (1.002.657 ha) se produjo durante el periodo 2004-2005. Entre esos años, “el paisaje de la región experimentó la transformación más grande y severa que jamás tuvo desde la prehistoria” (Leake, López y Leake 2016, 11).

El mismo estudio revela que los emprendimientos agrícolas y ganaderos ${ }^{7}$ afectaron una superficie total de 1.250 .000 ha. Entre el 2004 y el 2008 se produjo un crecimiento abrupto. Luego, como resultado de la implementación de la Ley de Bosques Nativos ${ }^{8}$, hubo un decrecimiento relativo y entre los años 2011 y 2012 - a pesar de estar vigente la normativa - hubo un nuevo auge, es decir, aumentaron los desmontes ilegales.

las tierras y que dependen de los recursos del bosque para su subsistencia. Muchos de ellos han sido violentamente desalojados o subsisten en pequeñas parcelas rodeadas de campos de cultivo.

7 En el Chaco salteño coexisten, además de la agricultura especializada en la producción de soja, otras empresas que se dedican a la producción de poroto y la ganadería vacuna; ambas actividades tienen una trayectoria histórica previa a la producción sojera. La ganadería se divide en dos tipos: una "tradicional", que es practicada por puesteros campesinos de origen criollo que no tienen títulos de las tierras ni deslindes de estas. Otra es de tipo capitalista, practicada por empresas privadas con mayor inversión en tecnología, que tienen la titularidad de las tierras y tienen deslindes o alambrados. Tras las normativas que prohibieron los desmontes para actividades agrícolas, algunas empresas reacomodaron su producción a la actividad ganadera que cuenta con mayores permisos.

8 Dicha ley suspendió el otorgamiento de autorizaciones de desmonte hasta que las provincias sancionaran una ley de Ordenamiento Territorial de Bosques Nativos (OTBN). En Salta esta se sancionó mediante la Ley Provincial 7543 reglamentada en el 2009. 
Figura 1. Deforestación del Chaco semiárido argentino

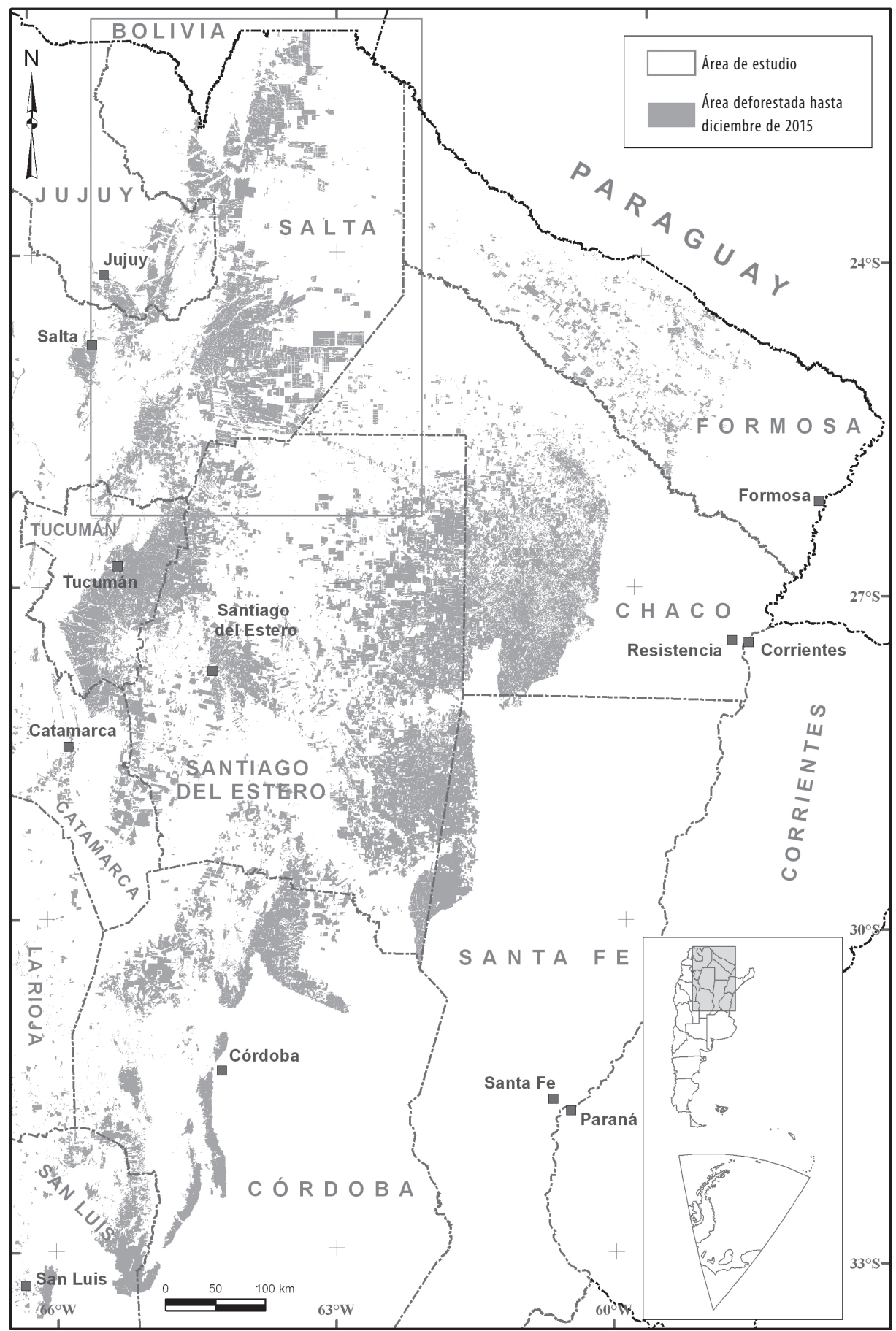

Fuente: Leake, López y Leake $(2016,12)$ 
Figura 2. Deforestación del Chaco salteño

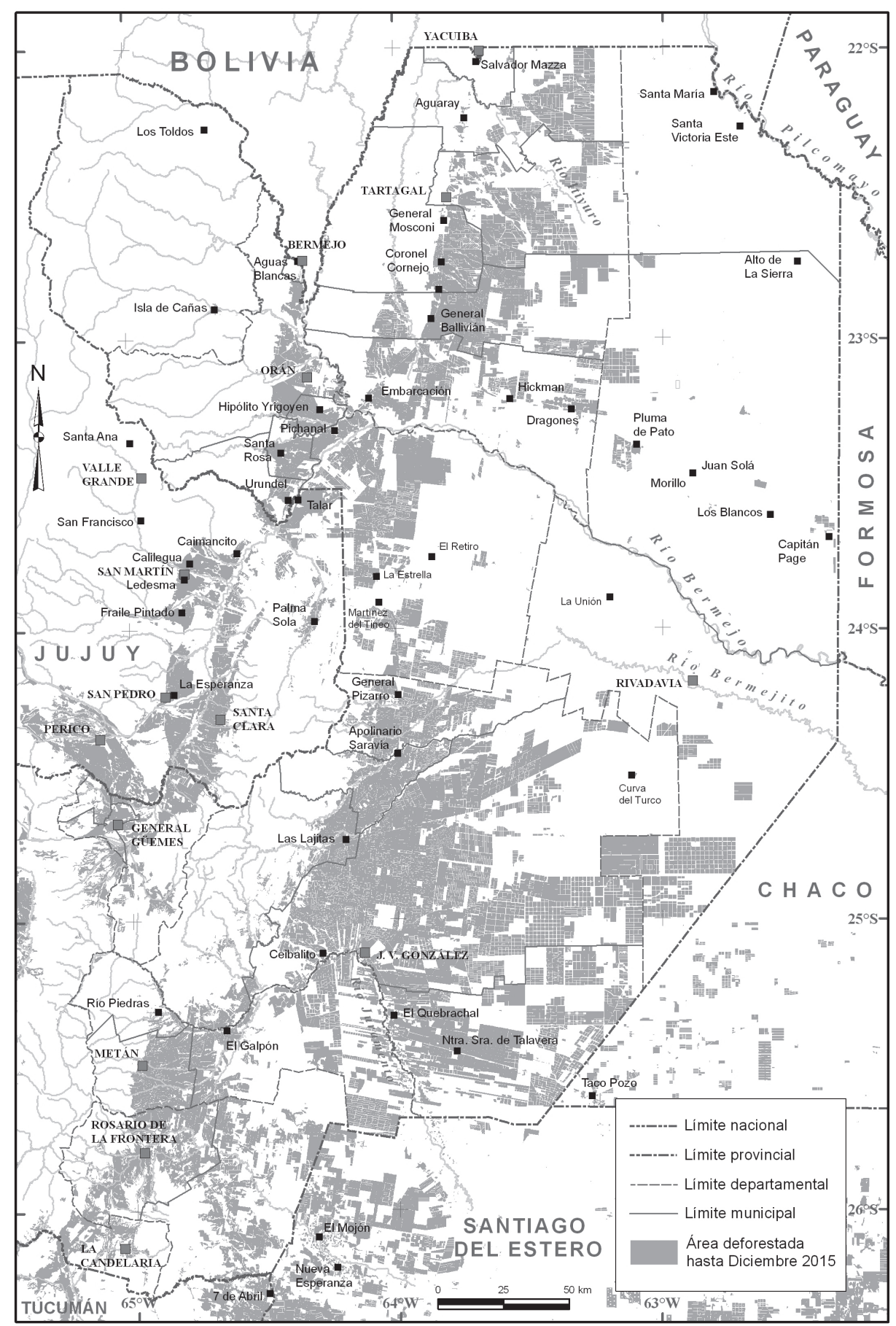

Fuente: Leake, López y Leake $(2016,13)$. Disponible en

https://www.researchgate.net/publication/315184196_La_deforestacion_del_chaco_salteno_2004-2015 
Figura 3. Chaco salteño: superficie deforestada hasta el 2015

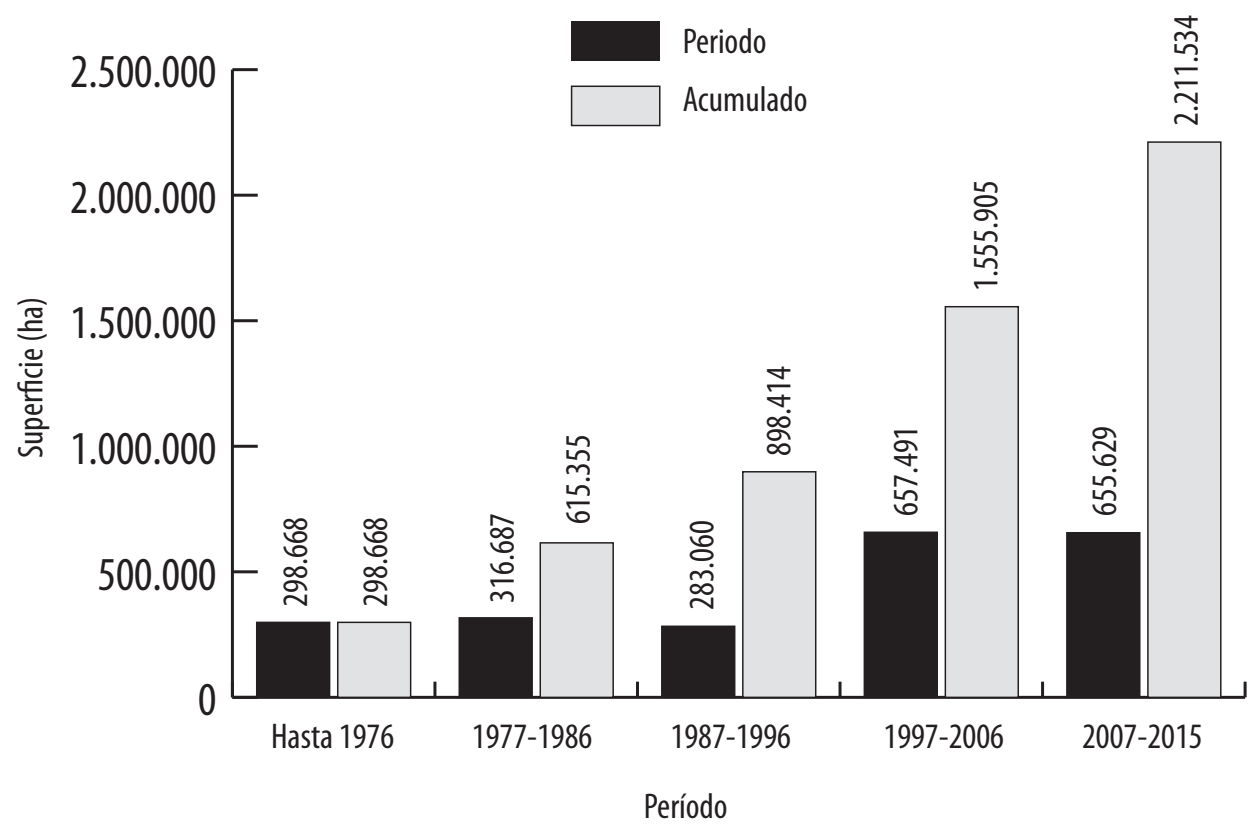

Fuente: Leake, López y Leake (2016, 14). Disponible en

https://www.researchgate.net/publication/315184196_La_deforestacion_del_chaco_salteno_2004-2015

Figura 4. Chaco salteño: superficie deforestada por año

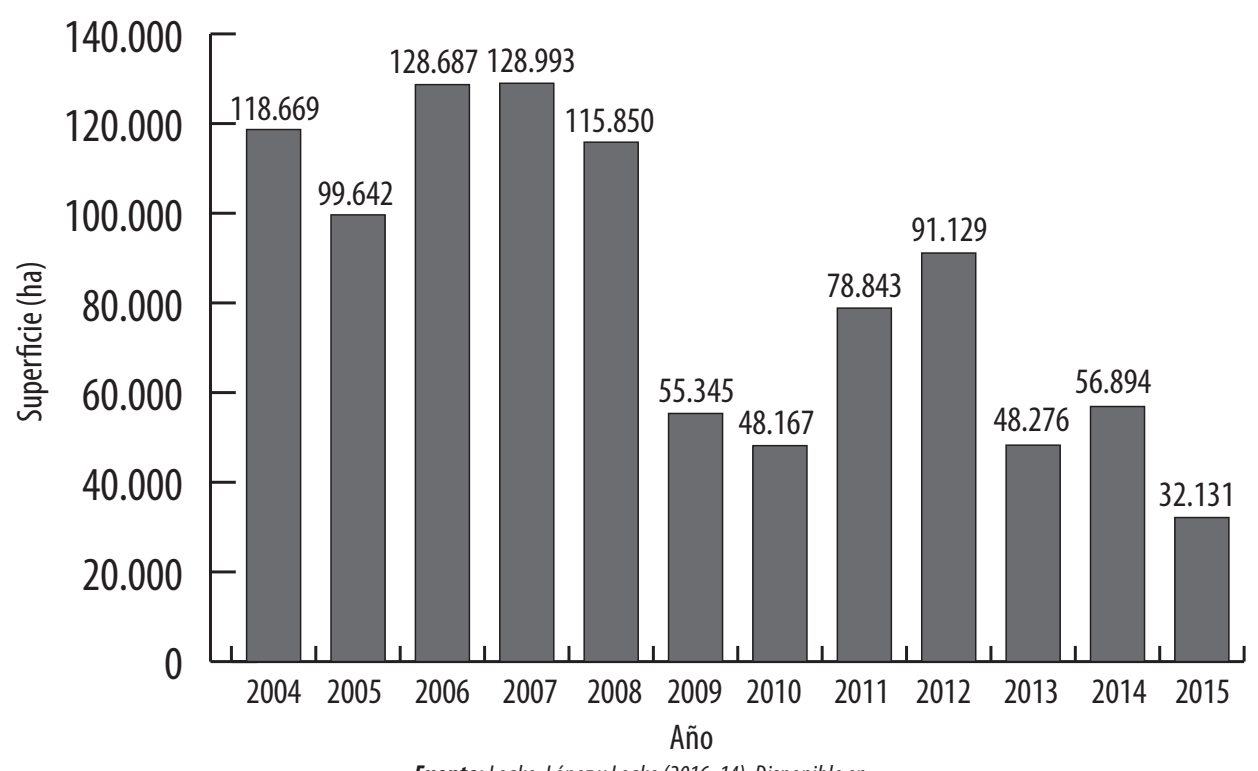

Fuente: Leake, López y Leake (2016, 14). Disponible en

https://www.researchgate.net/publication/315184196_La_deforestacion_del_chaco_salteno_2004-2015 
Tabla 1. Superficie afectada a nivel departamental, según uso

\begin{tabular}{l|c|c|c|c|c|c|c}
$\begin{array}{c}\text { Departa- } \\
\text { mento }\end{array}$ & $\begin{array}{c}\text { Superficie } \\
\text { afectada } \\
\text { (ha) }\end{array}$ & Ganadería & $\begin{array}{c}\text { Agricultura/ } \\
\text { ganaderia }\end{array}$ & Agricultura & $\begin{array}{c}\text { Aprov. } \\
\text { forestal }\end{array}$ & Forestación & Total \\
\hline Anta & 454.975 & $72 \%$ & $18 \%$ & $9 \%$ & $0 \%$ & $1 \%$ & $100 \%$ \\
\hline San Martín & 302.563 & $15 \%$ & $47 \%$ & $34 \%$ & $3 \%$ & $1 \%$ & $100 \%$ \\
\hline Rivadavia & 253.811 & $96 \%$ & $4 \%$ & $0 \%$ & $0 \%$ & $0 \%$ & $100 \%$ \\
\hline Orán & 115.907 & $6 \%$ & $51 \%$ & $40 \%$ & $4 \%$ & $0 \%$ & $100 \%$ \\
\hline Metán & 78.205 & $72 \%$ & $12 \%$ & $16 \%$ & $0 \%$ & $0 \%$ & $100 \%$ \\
\hline $\begin{array}{l}\text { Rosario de la } \\
\text { frontera }\end{array}$ & 39.276 & $50 \%$ & $38 \%$ & $12 \%$ & $0 \%$ & $0 \%$ & $100 \%$ \\
\hline Güemes & 8.242 & $23 \%$ & $22 \%$ & $55 \%$ & $0 \%$ & $0 \%$ & $100 \%$ \\
\hline
\end{tabular}

Fuente: Leake, López y Leake (2016, 24). Disponible en

https://www.researchgate.net/publication/315184196_La_deforestacion_del_chaco_salteno_2004-2015

Como se puede inferir de las figuras, la expansión de la frontera agropecuaria en el Chaco salteño — basada en la explotación extensiva y los agronegocios- ha reconfigurado los patrones de uso territorial. Además, siguiendo a Yudi (2009), estos procesos:

[...] han desorganizado los patrones de acumulación anterior, desenganchando producción de reproducción, acumulación e integración, de ese modo los cambios en los modelos productivos han impactado doblemente en la reproducción de la vida de sectores campesinos e indígenas: desvinculación del acceso a la tierra y los recursos y una exclusión del mercado de trabajo, ya que no existen actividades que requieran fuerza de trabajo. (2)

Los patrones de acumulación anterior a que se refiere esta cita son las actividades agroindustriales preexistentes, tales como la producción del azúcar, el poroto y otros cultivos que contrataban mano de obra indígena en grandes cantidades antes de su tecnificación. Estos fueron reemplazados en gran parte por la producción sojera, para cuya cosecha tampoco se contrata fuerza de trabajo.

Con respecto a la población de áreas rurales afectadas por los procesos más recientes de desmontes, encontramos dos grupos principales: los campesinos “criollos” y las comunidades de origen wichí. En el caso de los primeros, se trata de grupos dedicados a la ganadería extensiva o de tipo "tradicional” que llegaron a la región entre fines del siglo XIX y principios del XX en busca de pasturas para el ganado, sobre todo vacuno. En el caso de las comunidades wichí, se 
trata de grupos indígenas que ancestralmente ocuparon esta zona como parte de sus territorios de uso tradicional.

El desarrollo de la ganadería a "monte abierto" o de tipo tradicional fue fomentado a principios del siglo XX por las políticas de colonización, luego de la “pacificación” del Chaco a través de las campañas militares contra los indígenas. La ganadería tuvo un auge hasta la década de los años treinta y luego un declive por la falta de demanda y la degradación por sobrepastoreo. Esta práctica restó importantes superficies de territorios a los pueblos indígenas, en especial del pueblo wichí; sin embargo, luego de su declive y empobrecimiento, los puesteros de ganado continuaron coexistiendo en los parajes rurales del Chaco con poblaciones originarias, hasta la actualidad. Si bien existen tensiones propias de la historia de desposesión o despojo territorial, las relaciones de convivencia entre criollos e indígenas se mantienen en la vida cotidiana, a través de una serie de contraprestaciones de servicios de los últimos hacia los primeros en las faenas rurales, la utilización de pozos de agua por parte de ambos, la asistencia a escuelas públicas comunes y en general la vida social de los pueblos y parajes del interior del Chaco.

Tanto los criollos ganaderos, por su actividad económica, como los pobladores wichí requieren de superficies extensas de territorio para poder subsistir. Los primeros para la pastura del ganado y los segundos para obtener recursos de monte para su alimentación, que se basa en la caza, la recolección y la fabricación de artesanías. La figura 5 muestra cuáles son las áreas de uso tradicional del pueblo wichí; cada línea representa de manera aproximada la dirección y distancias recorridas para el abastecimiento de la caza, pesca o recolección.

Como mostramos en otros estudios basados en nuestro trabajo etnográfico (Flores 2011; Naharro, Álvarez y Flores 2015), la ampliación abrupta e incesante de la frontera agraria afectó de manera dramática la vida cotidiana y la subsistencia económica de los pobladores rurales indígenas y campesinos. Esta presión, objetivamente ejercida mediante la práctica de los desmontes en sus territorios, fue generando una serie de conflictos que con los años devinieron en situaciones cada vez más violentas. En primer lugar, el cercamiento de alambres sobre grandes superficies impidió paulatinamente la libre circulación de los pobladores, afectando el acceso a los recursos que estaban disponibles antes. Luego, en solo dos décadas, la deforestación masiva provocó la pérdida irreversible de fuentes de alimentación y medicinas extraídas del monte, la muerte de animales y plantas propias del lugar, junto con la desertificación del ambiente. El desarrollo agrícola y ganadero produjo también la escasez de agua para consumo diario, debido a su monopolización por parte de las empresas y otros impactos nocivos, 
Figura 5. Uso y ocupación indígena wichí

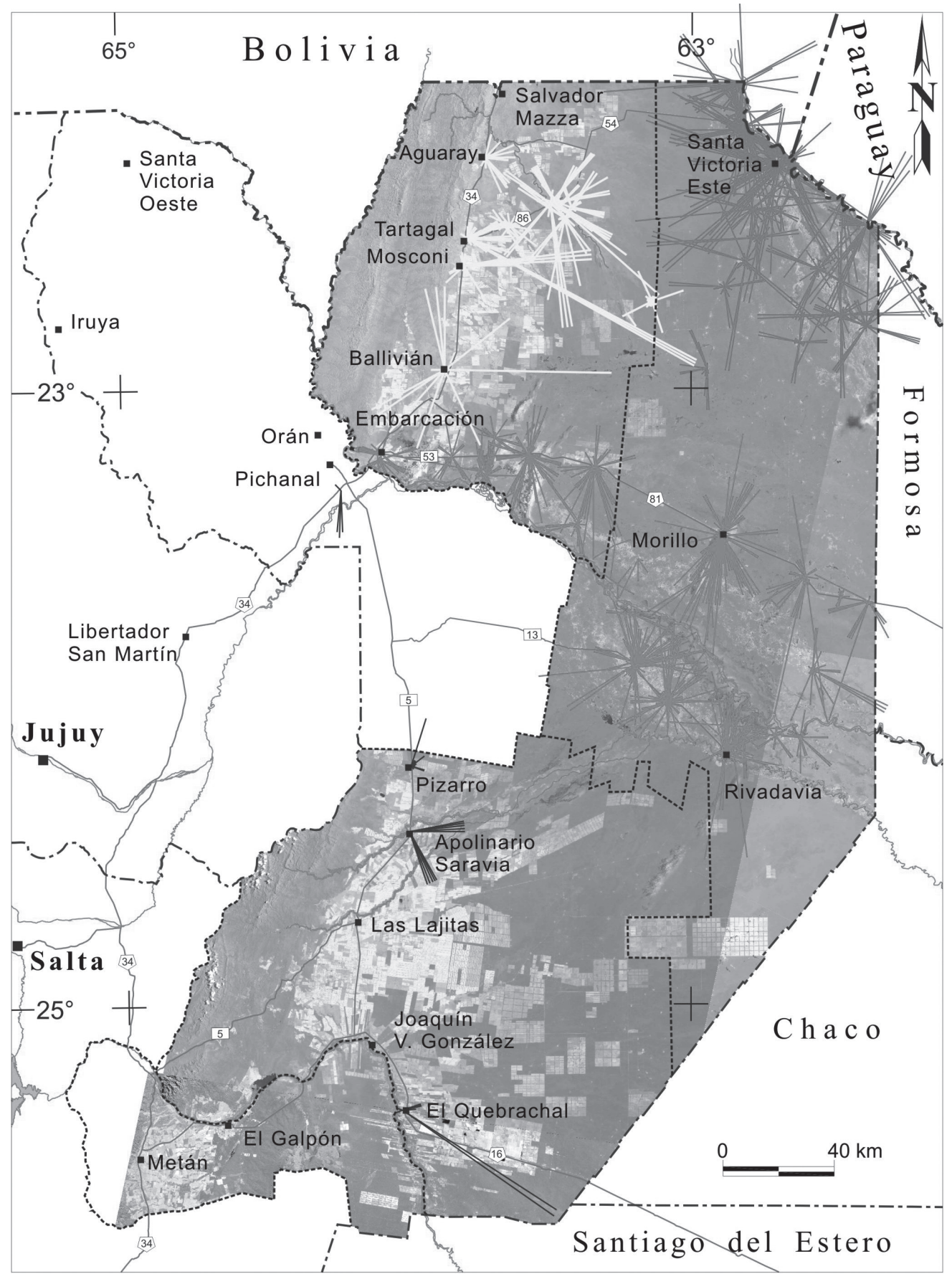

Fuente: Leake (2008,87). Disponible en: https://www.researchgate.net/publication/304747076_Los_pueblos_indigenas_cazadores_ y_recolectores_del_Chaco_Salteno_Poblacion_economia_y_tierras 
como la contaminación con agrotóxicos dada la cercanía a campos de cultivo que son fumigados mediante avionetas o máquinas.

A estos efectos directos sobre la vida de los pobladores rurales se suman otros impactos relacionados con la cuestión jurídica: la constante amenaza de desalojo por la falta de titulación de las tierras, la escasez de recursos para viabilizar los reclamos o la falta de acceso a la justicia, la intimidación y criminalización de la protesta social, entre otras consecuencias que incrementan la sensación de inseguridad y que fueron produciendo procesos de expulsión de población de áreas rurales a localidades urbanas en búsqueda de sustento (Duarte 2009; Naharro, Flores y Kantor 2009).

Uno de los datos que permiten analizar estas transformaciones es el grado de urbanización de la población indígena en los departamentos del Chaco salteño. En la siguiente tabla puede observarse comparativamente el crecimiento de la población indígena en áreas urbanas en el periodo intercensal 2001-2010. Este aumentó de un $48 \%$ a un 58,8\%, mientras que, respectivamente, los poblados rurales decrecieron de un 23,2\% a un 17,0\% y la población rural dispersa de un $28,2 \%$ a un $24,1 \%$.

Tabla 2. Grado de urbanización de poblaciones indígenas. Departamentos de Anta, Rivadavia, San Martín y Orán

\begin{tabular}{l|c|c|c|c}
\multicolumn{1}{c|}{ Población } & Indigena 2001 & Total 2001 & Indigena 2010 & Total 2010 \\
\hline Urbana $>=2.000$ & 23.835 & 259.300 & 28.549 & 308.636 \\
\hline Rural agrupada < a 2.000 & $48,60 \%$ & $76,20 \%$ & $58,80 \%$ & $81,22 \%$ \\
\hline & 11.389 & 32.639 & 8.273 & 30.900 \\
\hline Rural dispersa & $23,20 \%$ & $9,60 \%$ & $17 \%$ & $8,13 \%$ \\
\hline & 13.811 & 48.505 & 11.713 & 40.475 \\
\hline Total & $28,20 \%$ & $14,10 \%$ & $24,10 \%$ & $10,65 \%$ \\
\hline & 49.035 & 340.444 & 48.535 & 380.011 \\
\hline
\end{tabular}

Fuente: elaboración propia a partir de Censos Nacionales de Población, Hogares y Vivienda, 2001 y 2010.

Estas cifras muestran un proceso de despoblamiento rural que coincide con el avance de las superficies desmontadas en la zona.

En el caso de Orán, donde la frontera agropecuaria ha sido más tempranamente realizada, las ciudades muestran mayor grado de urbanización de las poblaciones indígenas (Yudi 2009). En este departamento la agricultura es la actividad principal; allí se encuentra un ingenio azucarero que aglutinó hasta los 
años setenta a gran cantidad de mano de obra indígena que trabajaba para la zafra. Luego de esa década, con la tecnificación de la cosecha, la gran mayoría quedó desvinculada del trabajo temporario y fue congregándose en asentamientos periurbanos o en fincas de propiedad privada. En Orán la superficie desmontada ${ }^{9}$ se incrementó de 12.763 ha en el 2004 a 30.154 ha en el 2007, llegando a una superficie de 96.084 ha en el 2017. La población indígena urbana pasó del 73,5\% en el 2001 al $90 \%$ en el 2010.

Tabla 3. Grado de urbanización de poblaciones indígenas del departamento de Orán

\begin{tabular}{l|c|c|c|c}
\multicolumn{1}{c|}{ Población } & Indígena 2001 & Total 2001 & Indígena 2010 & Total 2010 \\
\hline Urbana & 11.195 & 110.716 & 13.793 & 128.332 \\
\hline & $73,50 \%$ & $89,30 \%$ & $90 \%$ & $93,40 \%$ \\
\hline Rural agrupada & 598 & 3.180 & 34 & 1.143 \\
\hline & $4,20 \%$ & $2,60 \%$ & $0,20 \%$ & $0,80 \%$ \\
\hline Rural dispersa & 2.287 & 10.133 & 1.467 & 7.990 \\
\hline & $16,20 \%$ & $8,20 \%$ & $10 \%$ & $5,80 \%$ \\
\hline
\end{tabular}

Fuente: elaboración propia a partir de Censos Nacionales de Población, Hogares y Vivienda 2001 y 2010.

El departamento de Anta es el que mayor cantidad de hectáreas deforestadas tiene. En el año 2004 contaba con unas 137.395 ha desmontadas; en el 2007, con 281.587 ha, y en el 2017 alcanzó las 495.258 ha. Este departamento, a diferencia de los restantes, no tiene un alto porcentaje de población indígena (esta representa un $2 \%$ del total). Sin embargo, en los datos censales se observa que dentro de este conjunto poblacional más del $50 \%$ habita en zonas urbanas, mientras que poco más del $40 \%$ lo hace en zonas rurales, y este porcentaje se mantiene casi constante en el periodo 2001-2010.

Tabla 4. Grado de urbanización de poblaciones indígenas. Departamento de Anta

\begin{tabular}{l|c|c|c|c}
\multicolumn{1}{c|}{ Población } & Indígena 2001 & Total 2001 & Indígena 2010 & Total 2010 \\
\hline Urbana & 527 & 31.605 & 599 & 39.156 \\
\hline & $53,40 \%$ & $63,40 \%$ & $54,10 \%$ & $68,60 \%$ \\
\hline Rural agrupada & 94 & 8.530 & 88 & 10.143 \\
\hline & $9,50 \%$ & $17,10 \%$ & $7,90 \%$ & $17,80 \%$ \\
\hline
\end{tabular}

9 Las cifras de superficies desmontadas por departamento fueron calculadas tomando como punto de partida el 2001, con base en información de: monitoreodesmonte.com.ar 


\begin{tabular}{l|c|c|c|c}
\multicolumn{1}{c|}{ Población } & Indígena 2001 & Total 2001 & Indígena 2010 & Total 2010 \\
Rural dispersa & 368 & 9.706 & 420 & 7.772 \\
\hline & $37,30 \%$ & $19,50 \%$ & $37,90 \%$ & $13,60 \%$ \\
\hline Total & 987 & 49.841 & 1.107 & 57.071 \\
\hline & $100 \%$ & $100 \%$ & $100 \%$ & $100 \%$ \\
\hline
\end{tabular}

Fuente: elaboración propia a partir de Censos Nacionales de Población, Hogares y Vivienda, 2001 y 2010.

En el departamento de San Martín, segundo en cantidad de hectáreas deforestadas, se pasó de una cifra de 38.481 ha desmontadas en el año 2004 a un salto cuantitativamente importante de 104.865 ha en el 2007, tendencia que continuó hasta el 2017, sumando 20.735 ha. A diferencia del departamento de Anta, el porcentaje de población indígena es de un 15\% del total poblacional. En el periodo 2001-2010, la población que vivía en áreas urbanas pasó de un 47,7\% a un 56\%. Mientras tanto, la población indígena de áreas rurales (congregadas en pequeños pueblos) se mantuvo casi estable (del 32\% al 30\%) y la de áreas rurales dispersas bajó de un 20,2\% a un 13,4\%. Estas cifras pueden mostrar el proceso de expulsión de población indígena de áreas rurales y un grado de urbanización cada vez mayor de esta.

Tabla 5. Grado de urbanización de poblaciones indígenas. Departamento de San Martín

\begin{tabular}{l|c|c|c|c}
\multicolumn{1}{c|}{ Población } & Indígena 2001 & Total 2001 & Indígena 2010 & Total 2010 \\
\hline Urbana & 11.197 & 113.301 & 12.311 & 131.959 \\
\hline & $47,70 \%$ & $81,40 \%$ & $56 \%$ & $85 \%$ \\
\hline Rural agrupada & 7.515 & 13.122 & 6.722 & 14.552 \\
\hline & $32 \%$ & $9,40 \%$ & $30,60 \%$ & $9,40 \%$ \\
\hline Rural dispersa & 4.744 & 12.781 & 2.952 & 8.739 \\
\hline & $20,20 \%$ & $9,20 \%$ & $13,40 \%$ & $5,60 \%$ \\
\hline Total & 23.456 & 139.204 & 21.985 & 155.250 \\
\hline & $100 \%$ & $100 \%$ & $100 \%$ & $100 \%$ \\
\hline
\end{tabular}

Fuente: elaboración propia a partir de Censos Nacionales de Población, Hogares y Vivienda, 2001 y 2010.

Por último, el departamento de Rivadavia, ubicado al este de Salta, no es apto para actividades agrícolas debido a sus características climáticas semidesérticas. El $96 \%$ de la actividad productiva se concentra en la ganadería, principalmente de tipo tradicional, aunque en los últimos años se iniciaron nuevos proyectos productivos de corte capitalista, para los cuales se desmontaron 207.356 ha de superficie, entre el 2001 y el 2017. En esta zona, alrededor del $35 \%$ 
de la población total pertenece a comunidades indígenas. En este caso puede extraerse alguna particularidad con respecto a la población rural indígena dispersa que mantiene un porcentaje relativamente similar entre los años 2001-2010, con un leve aumento de un $61 \%$ a un $67,7 \%$, mientras que la cifra de indígenas que viven en sectores urbanos aumentó de un 8,7\% a un 18,2\% y la de los poblados intermedios bajó de un 30,3\% a un 14\%. Cabe destacar que en la superficie total departamental solo dos municipios cuentan con características de urbanización (Santa Victoria Este y Rivadavia).

Tabla 6. Grado de urbanización de poblaciones indígenas. Departamento de Rivadavia

\begin{tabular}{l|c|c|c|c}
\multicolumn{1}{c|}{ Población } & Indígena 2001 & Total 2001 & Indígena 2010 & Total 2010 \\
\hline Urbana & 916 & 3.678 & 1.846 & 9.189 \\
\hline & $8,70 \%$ & $13,40 \%$ & $18,20 \%$ & $30,40 \%$ \\
\hline Rural agrupada & 3.182 & 7.807 & 1.429 & 5.062 \\
\hline & $30,30 \%$ & $28,50 \%$ & $14,10 \%$ & $16,70 \%$ \\
\hline Rural dispersa & 6.412 & 15.885 & 6.874 & 15.974 \\
\hline & $61 \%$ & $58 \%$ & $67,70 \%$ & $52,90 \%$ \\
\hline Total & 10.510 & 27.370 & 10.149 & 30.225 \\
\hline & $100 \%$ & $100 \%$ & $100 \%$ & $100 \%$ \\
\hline
\end{tabular}

Fuente: elaboración propia a partir de Censos Nacionales de Población, Hogares y Vivienda, 2001 y 2010.

A partir de lo anterior podemos visualizar que en la región del Chaco salteño el departamento de San Martín ocupa el segundo lugar en cuanto al desarrollo de la actividad agrícola (34\%) y agrícola-ganadera (47\%) —después de Orán, que concentra el $40 \%$ de actividades agrícolas y el 51\% de actividades agrícolas y ganaderas-. También es segundo en porcentaje de población indígena con un 15\%, con respecto a Rivadavia que tiene el 38\%, a Orán con el $11 \%$ y a Anta con el $2 \%$. Para los fines de este trabajo, los datos mencionados nos permiten aproximarnos a las consecuencias de los agronegocios y su impacto en la población indígena.

Este breve acercamiento estadístico visibiliza la manera como la expansión del capitalismo agrario ha reconfigurado significativamente los territorios del Chaco salteño y que la población rural ha tendido a disminuir en las últimas décadas. Como apuntamos al principio, esta reconfiguración territorial se relaciona con un nuevo régimen de acumulación de capital, cuya contracara es la desposesión o despojo de bienes comunes (como el agua, la tierra y la biodiversidad) a las poblaciones locales. En otros trabajos (Naharro y Flores 2015) hemos mostrado cómo las políticas agrarias en Salta son fomentadas estatalmente mediante el discurso del desarrollo como paradigma hegemónico, que concibe a la 
naturaleza como un recurso a ser explotado y a la producción a gran escala como un imperativo para el progreso. En este discurso no solo se pierden de vista otras formas preexistentes de uso y valoración del territorio de las poblaciones rurales sino que se las percibe como un obstáculo.

Si bien los datos estadísticos nos permiten conocer a nivel macro los efectos de políticas agrarias y su impacto demográfico, no hacen posible tener una visión en mayor profundidad sobre la situación que atraviesan los pobladores afectados por estos procesos. A continuación, realizaremos un acercamiento a la visión de los pobladores indígenas wichí de diferentes localidades urbanas y rurales del departamento de San Martín para poder comprender lo que significa experimentar estas situaciones en su vida cotidiana.

\section{Resistir en el campo o migrar a la ciudad}

Ante las nuevas transformaciones del ambiente que modificaron objetivamente las condiciones de vida de las comunidades indígenas ${ }^{10}$, las alternativas de subsistencia se tensionaron entre dos posibilidades. Continuar resistiendo ${ }^{11}$ el avance de los desmontes y subsistir en sus lugares, cada vez con menos recursos, o migrar a las ciudades y adaptarse a ellas viviendo en condiciones de exclusión y extrema pobreza. Otra forma de resistencia es la que se describe en este artí-

10 En este apartado nos basamos en registros de nuestras observaciones en terreno y entrevistas realizadas en el contexto, así como en testimonios obtenidos por otros especialistas (antropólogos y técnicos) que realizan trabajos de investigación y acciones con las comunidades del departamento de San Martín, especialmente en las localidades de Ballivián y Embarcación, algunos de los municipios más recientemente afectados por el avance de los desmontes. Nuestro trabajo de campo inició en el 2005 con viajes a la zona y estadías periódicas hasta el 2015 en los diferentes municipios del departamento de San Martín, tanto en áreas rurales como urbanas. En este periodo se observaron de manera directa los cambios ocurridos y se recogieron testimonios de las personas que viven en diferentes comunidades, parajes, pueblos y ciudades (véase la nota 2).

11 Respecto a las resistencias indígenas propias de la zona, trabajé ese tema en mi tesis doctoral (Flores 2011). Aquí solo cabe mencionar que las movilizaciones indígenas, en particular del pueblo wichí, han sido articuladas con apoyo de organizaciones civiles, religiosas y educativas, y que siguieron diferentes vías: la burocrático-administrativa, la protesta social y la judicial. Los repertorios de protesta incluyeron los cortes de ruta, las cadenas humanas para detener topadoras, la "toma" de vehículos, los cortes de alambre, entre otras. La respuesta más común del Estado ha sido la cooptación, criminalización y represión de dirigentes y comunidades. En la vía judicial se han realizado pedidos de amparos colectivos y demandas que incluyen juicios contra el Estado nacional, provincial y empresarios particulares. Los procesos judiciales, que por lo general demoran años, en algunos casos pusieron freno temporal a los desmontes mientras que las comunidades vivieron cotidianamente estos procesos enfrentando amenazas de empresarios o funcionarios del Estado. 
culo: continuar viviendo en sus territorios a pesar de las fuertes presiones para su expulsión. Permanecer en sus asentamientos (sin moverse, como podían hacerlo antes, cuando había monte) es una elección de resistencia al proceso expansivo de los monocultivos; tal como lo plantea Zibechi (2014): “el territorio es la trinchera y el cuerpo la barricada” (84). El monte fue y sigue siendo para las comunidades wichí el núcleo central de su relación con la cultura, ya que de él depende su forma de subsistencia basada en las prácticas de caza y recolección ${ }^{12}$. Su pérdida simboliza no solo la ruptura del vínculo con el territorio sino también la enajenación de su propia identidad como pueblo, debido a que se borran materialmente todas sus referencias. En la manera de procesar tales cambios existen diferentes asociaciones con el pasado y una evocación del significado de la pérdida. Desde el punto de vista de los wichí, la vida en el monte es sinónimo de paz y libertad. Por el contrario, la pérdida de estos aspectos representa una alteración de este equilibrio que genera enfermedad y muerte.

Francisco actualmente vive en una comunidad wichí periurbana de la ciudad de Embarcación. Se crio en medio del proceso de poblamiento de colonos en el lugar y aún tiene el recuerdo de cómo era la vida cuando había monte:

Porque el indio antes... buscaba sus medios de vida. Por ejemplo, en tiempo de pesca se iba al río, en tiempo de algarroba se iba al campo... ¡era libre, era libre! [...] el territorio de ellos era libre, no había alambrado, no había, tenía su libertad de caza, pesca, para buscar miel, para buscar su alimento silvestre, ¿no? [...] todo era monte. Embarcación, cuando yo he conocido eran dos calles no más [...] la ruta 34 era enripiado nada más. Y bueno... con el tiempo ya entró todo esto [...] ¡todo Embarcación ha sido asentamiento indígena! Nada más que, como le digo, ha sido asentamiento en una parte y cuando menos acuerdo ya "este terreno tiene dueño”. (Francisco ${ }^{13}, 62$ años. Embarcación, 2006)

Cuando aún "había monte” —antes de 1970-, las familias indígenas de San Martín podían combinar dos formas de vida complementarias. Una correspondiente a la subsistencia basada en el trabajo de la tierra, en las prácticas de caza y recolección, y otra que podía servir como complemento: la labor temporaria en los ingenios, obrajes y servicios en las ciudades o fincas de la zona.

En el relato de la gente se construye un "antes”: “cuando había monte” era un tiempo en que "se iba a vivir donde había fruto o animales” o fuentes de agua.

12 En otros trabajos hemos detallado el contexto histórico de estudio y la forma de vida del pueblo wichí. Para ampliar, véanse Flores (2011); Naharro, Álvarez y Flores (2015).

13 Los nombres de las personas entrevistadas han sido modificados, mientras que en los testimonios extraídos de documentales públicos se indican los nombres reales. 
Esto se significa en el presente como una forma de vida pasada, tanto de "los antiguos” como de los abuelos del presente. El monte también marca un contraste entre la vida urbana y la de las zonas rurales, porque aún se reconoce que en las áreas del Chaco “donde hay todavía monte”, esas prácticas se mantienen vigentes. Los descendientes wichí más jóvenes, asentados en la periferia de las ciudades, ya no tienen memoria de esa época; sin embargo, la reconstruyen a partir del relato de sus abuelos que sí la vivieron y les contaron.

Juan tiene alrededor de cuarenta años, nació en el pueblo de Ballivián y actualmente es cacique de una comunidad wichí. Él reconstruye ese pasado desde el relato de sus abuelos que vivieron en el lugar antes del proceso de urbanización:

En esa época [década de los cincuenta] todo era lindo [...] Yo no he visto lo que ha pasado. Pero cuento lo que me han contado mis abuelos... de esos lugares que ya no existen. Y me contaban ellos. Decían en aquella época... todos los jóvenes, niños, hasta las mujeres eran robustas... igordas, fuertes, sanas! Y yo le pregunto. "Bueno ¿Por qué?”. Y dicen, "bueno: ¿sabes por qué? Porque para nosotros el monte es vida, el monte es la vida. Porque en el monte comemos algarroba, comemos mistol y después comemos chañar, comemos la fruta de la mora, comemos animales del monte... ¡todo sano, sano!, todo natural. (Juan, Quebrachal 1Ballivián 2009) ${ }^{14}$

En los años setenta se realizaron los primeros desmontes para la siembra de poroto, actividades que los indígenas visualizaban positivamente porque eran incluidos como mano de obra temporaria. En este periodo empezaron algunas migraciones de los indígenas que vivían en el campo a los pueblos cercanos. Ellos comentan sus primeras experiencias laborales, algunas de las cuales incluyen su participación en la tarea de los desmontes:

Y llegó tiempo cuando nosotros hemos salido [de Cuchuy] [...] nosotros no sabíamos qué eran los desmontes, pues. Bueno, han tomado la gente y la gente han salido a mirar y a ver qué es lo que estaba haciendo esa máquina. Entonces todo eso lo veían, lo miraban. Nosotros no hemos conocido qué es lo que eran las máquinas, ¿ve? Entonces el desmonte que le estaba haciendo... por esa época, estaba saliendo la gente del Chaco porque los tomaban, les daban trabajito... entraba al desmonte al deschampe, destronque, todo eso. Entonces ya la gente hemos empezado a salir con toda la familia, ¿ve? Entonces ya nos hemos venido a quedar ya para esta parte y ya se hemos quedado acá. (Segundo, Ballivián, 2011) ${ }^{15}$

\footnotetext{
14 Entrevista realizada por Paolo Sanguinetti del Proyecto Ciunsa 1968.

15 Entrevista realizada por Paolo Sanguinetti del Proyecto Ciunsa 1968.
} 
A diferencia del relato anterior, en este caso se percibe la "salida" de la comunidad como una opción posible que genera curiosidad y a la vez una necesidad de producir ingresos. Por otra parte, la adaptación a la vida urbana implicó, para los que migraban de comunidades rurales, el abandono total o parcial de sus costumbres en todos los aspectos de su vida cotidiana, principalmente la vestimenta, la alimentación y la relación con el consumo, por la incorporación de otros hábitos que tomaron de su convivencia con los “criollos”:

Y bueno, cuando uno era joven trabajaba y era quince años, lo pagaban. Y bueno ya hemos conocido cómo era la plata, mejor dicho. Y bueno ya hemos conocido cómo nos tenemos que vestir, qué pantalón tenemos que comprar [...] pero anteriormente no, nosotros los paisanos usamos una camisa, pero es una chaguar ${ }^{16}$, mejor dicho, ¿ve?, entonces nosotros, los varones, usábamos chiripa ${ }^{17}$, como se dice, ¿no? Todo chaguar, pero como vestido. Todo eso nosotros usábamos. Pero cuando había de ese trabajo, los empresarios han tomado a nosotros... Recién hemos conocido cómo era la plata, cómo tenemos que divertirse con la plata, qué tenemos que comprar, todo eso. [...] Hasta que nosotros nos acostumbramos, que por ahí otro dice "no porque por ahí mi hijo está trabajando... ahora mi hijo está comprando un poco de mercadería”. Y ya se la estamos dejando poco de la fruta de la que nosotros vivimos, de la miel. Y bueno, ya hemos conocido qué era la harina como se decían, ¿ve? Y ya hemos conocido cómo es que eran los fideos... los viejitos no comían fideos. No comían porque no conocían. Ellos de lo que conocían era del chaguar, todo eso. De miel, algarroba, chañar... Pero hasta que un momento que se han acostumbrado la gente. Se han acostumbrado, después ya han empezado a caminar entre medio de los criollos... y así nos amansamos... por su trabajo. ${ }^{18}$ (Rolando, Ballivián, 2011)

Pasada esta época de su participación en trabajos temporarios - ya fuera en los desmontes o la cosecha de poroto-, hacia mediados de la década de los noventa la tecnificación de las tareas agrícolas fue prescindiendo de su contratación:

Yo trabajé mucho en Sierras San Antonio [una empresa agrícola], pero ahora con las maquinarias no tenemos beneficio de trabajo. Todo es

16 El chaguar es una planta también denominada caraguatá (Bromelia hieronymi). De ella se obtiene una fibra con la cual las mujeres wichí confeccionan hilos resistentes y tejen bolsas (yicas) utilizadas para transportar piezas de caza, pesca u objetos. Actualmente también se confeccionan otros elementos ornamentales que son vendidos a comercios de artesanías. La venta de artesanías de este material es característico del pueblo wichí y, ya sea directa o a intermediarios, constituye un aporte monetario (aunque exiguo) de importancia para las familias.

17 Es una prenda que cubre la parte inferior del cuerpo y consiste en una manta colocada en forma de pañal ceñida con faja. 
maquinaria, va directo a la trilla, hasta la carga de bolsa de mil kilos. Entonces por eso estamos sin trabajo. A veces tenemos una changüita pero no dura ni un año y bueno... no tenemos un trabajo seguro. (Daniel, Pastor Senillosa, Ballivián, 2011 ${ }^{19}$

Al ingresar en el mercado laboral y trasladarse a los poblados y centros urbanos, algunos reconocen que fueron partícipes de la propia degradación de la tierra a la que ya no pueden regresar:

En el año 80 han empezado los desmontes y en adelante ya se iba ampliando, ampliando cada vez más y más, hasta el día de hoy que ya de monte no queda casi nada. Primero era algo como que nos beneficiaba porque había mucho trabajo. Cuando ya todo se ha desmontado, se siembra la soja y ocupan gente que hace el desmalezamiento o "desyuyada”, como decimos nosotros [...] Después han pasado los años, con el avance tecnológico ya no se ocupa la mano de obra, ya nosotros quedamos sin trabajo, no se ocupa mucho personal en el campo. (Félix, Pastor Senillosa, Ballivián, 20112 ${ }^{20}$

En el interior del Chaco este proceso de pérdida de trabajo fue vivido y recordado de manera similar. Pedro, que vive en San José, una comunidad rural bordeada de campos de cultivo, comenta:

El primero ha sido en el año 75, cuando han empezado los desmontes. Primero han desmontado a Ballivián (pueblo) y de ahí han ido para Cornejo [al norte, sobre ruta 34] y de ahí para acá [zona rural del este de Ballivián]. En la primera entrada había trabajo en Ballivián y después ya no, ahora todo es maquinaria. No hay "bolsero", ahora son bolsas de mil kilos, todo trae la máquina. Y cuando hay desmonte no contratan gente de acá, traen de otro lado. (Ballivián, 2011) ${ }^{21}$

Dos procesos simultáneos se relatan como una pérdida irrevocable, no solo material sino también cultural y espiritual: la destrucción del monte y la falta de trabajo. Ante estos procesos se remite al pasado reciente con una nostalgia de lo que ya no podrá ser y a la vez angustia por el futuro en el cual no se logra visualizar una continuidad.

En las comunidades rurales que aún habitan en reductos de monte rodeados de cultivos, las condiciones de existencia se alteraron drásticamente. En

19 Testimonio extraído del video Los desmontes (Asociana). Entrevista realizada por Paolo Sanguinetti del Proyecto Ciunsa 1968.

20 Entrevista realizada por Paolo Sanguinetti del Proyecto Ciunsa 1968.

21 Testimonio extraído del video Los desmontes (Asociana). Entrevista realizada por Paolo Sanguinetti del Proyecto Ciunsa 1968. 
estos casos en que la dependencia de la naturaleza para la subsistencia es mayor, la forma de estar en el territorio según las costumbres propias se vuelve cada vez más insostenible. Teresa, de la comunidad wichí de Corralito, otro paraje rural rodeado de campos de cultivo, comenta este proceso desde su propia vivencia:

Yo sigo viviendo aquí, no podría ir a ningún otro sitio. Yo siempre fui de aquí nomás, me crie en este lugar. Mis padres ya no viven. Todo esto han sido nuestros lugares. Los recorrimos. Por eso siento una gran aflicción por la tierra desde que empezaron a destruirla, pues a ella recurrimos. Era nuestro único recurso para alimentarnos. Los animalitos, nuestro principal alimento. Salíamos a buscar miel del monte. Por eso me da tanta tristeza [...] Todos estos lugares hemos recorrido. Un lugar llamado Sulaj Päsat (Hocico de Oso) es nuestro lugar. Ye'la Lihitey (Esqueleto de Anta) también otro lugar, Fwiyhol (Carbones). Allá es Hataj (Cebil), recorrí todo esto con mis padres. Allí un lugar llamado Ye’la Y’amhuy (Estiércol de Anta). Allí otro L’ataj Tahy (Caballo Habla), otro Tewo Lhetek (Naciente del Río), otro es W’aj Wumek (Antiguo Cauce) todo eso hemos recorrido. Amamos esta tierra... (Teresa, 43 años, Corralito, 2011)

En este relato también se marca el contraste entre el deseo de permanecer en el lugar por no ver un horizonte posible en la ciudad, donde la vida está sujeta a muchos cambios en las costumbres que pasan a depender exclusivamente del dinero. Como puede verse, la existencia del monte expresa el modo de ser indígena y la posibilidad de desarrollar la vida con base en la cultura, ya sea de manera total o combinada con otras fuentes de ingreso.

También, en muchos casos sucedió que, al moverse del lugar, como es usual en los wichí por su cultura itinerante, al regresar a los asentamientos encontraron todo desmontado. En ese sentido, permanecer en el lugar aun a costa de sufrir hambre, se ha convertido en una forma de resistir el avance de las máquinas sobre sus territorios.

Aunque hay otros que se van y abandonan la tierra a causa del hambre. Una vez estuve en cama a causa del hambre. Conseguía un poco de harina y la hervía para toda la familia... se destruyeron los algarrobos, ya no tenemos qué comer, el agua, nos han perjudicado. Todo donde hemos estado antes ha sido desmontado, ya son fincas, todos lados... Mis padres ya murieron y no intentaré irme a otro lugar, no me acostumbro al pueblo, no puedo, no puedo... Estoy arriesgando mi vida de estar aquí [...] Me aferro a este lugar, aunque se enojen conmigo. Si me quieren matar que me maten, ni aun así dejaré de estar aquí. (Teresa, Corralito, 2011) ${ }^{22}$

22 Testimonio extraído del video Los desmontes (Asociana). Entrevista realizada por Paolo Sanguinetti del Proyecto Ciunsa 1968. 
A diferencia de los testimonios de personas wichí que migraron en décadas previas por la contratación de puestos temporarios, lo que se observa en estos otros es que las nuevas migraciones wichí de áreas rurales a los pueblos y ciudades cercanas tienen como causa el hambre y la falta de agua. A pesar de ello hay personas que prefieren quedarse en el lugar y seguir resistiendo, aun bajo estas condiciones extremas, por mantener sus costumbres y el vínculo con el territorio de pertenencia. La falta de autonomía para conseguir los propios alimentos hace que la vida de las comunidades dependa de los subsidios o entrega de recursos por parte de la municipalidad ${ }^{23}$. Dos de estos recursos, las raciones de alimento y el agua, son vistos y sentidos como insuficientes, a la vez que genera situaciones de dependencia y abusos por parte de quienes los distribuyen desde el Estado.

Por el tema de la comida, eso es lo más grave que nosotros tenemos. Son pequeñitos los bolsoncitos que nos dan, ¡no nos alcanza ni para dos días! Claro, si tiene 1 kilo de harina, $1 / 2$ de fideo, $1 / 4$ de yerba y 1 kilo de sémola y jeso es todo!... El agua falta, eso es lo que más estamos sufriendo, porque nosotros tenemos que rogarle a la municipalidad que nos mande agua. A veces voy a pedir... ahora no porque no tengo bicicleta, no puedo ir. Le digo "mire, yo necesito agua”. Dice: "bueno, mañana temprano te voy a mandar”. Entonces vuelvo y espero. A veces tengo que esperar tres días y no vienen iy tengo que volver a ir otra vez! Recién me traen. (Pedro, San José-Ballivián, 2011) ${ }^{24}$

Sin respuesta del Estado, la situación se va tornando insostenible: "Hay veces que no me queda otra que entrar en la finca a robar lo que se siembra. Pero me siguen y me corren... pero qué va a ser... así es cuando falta alimento” (Teresa, Corralito, 2011 $)^{25}$.

De manera similar a las personas de las comunidades rurales, los que viven en el pueblo atraviesan esta crítica situación con respecto a la obtención de alimento. Aunque en el pueblo se consigan “mercaderías”, además de ser escasas, no son vistas como buena alimentación. El cambio de la dieta de los wichí, como consecuencia de los desmontes, también se relaciona con la desnutrición de los niños:

Entonces mi abuelo... dice ahora, en esta época, nosotros vemos que... que hay niños desnutridos, jóvenes desnutridos, todos delgaditos, enfermos,

23 Los bolsones alimentarios que entrega el municipio, en este caso de Ballivián, son específicos para las comunidades originarias. Las compañías sojeras no tienen incidencia en esta prestación.

24 Testimonio extraído del video Los desmontes (Asociana). Entrevista realizada por Paolo Sanguinetti del Proyecto Ciunsa 1968.

25 Testimonio extraído del video Los desmontes (Asociana). Entrevista realizada por Paolo Sanguinetti del Proyecto Ciunsa 1968. 
decaídos [...] porque ya no hay ni comida [...] todo eso sale a causa del desmonte, a causa del desmonte sale todo eso. ¿Por qué? Porque decía mi abuelo que el monte es la vida de los originarios, ¡la vida! [...] entonces yo le digo, "abuelo, entonces nosotros que estamos en el pueblo... entonces no es vida lo que llevamos nosotros”. Dice: “ino!, la vida que llevan ustedes en el pueblo no es vida...”. ¿Por qué? "Porque en el pueblo no tienen libertad, no tienen libertad como tenemos nosotros antes. En el pueblo van a vivir encerrados, no van a poder cazar, no van a poder darle alimentos naturales a los hijos. Y los hijos de ustedes van a vivir desnutridos, van a vivir enfermos”, iy como qué!... Hasta los hijos de nosotros ahora mueren de desnutrición. Entonces dice: "Ahora que están en el cielo no es vida”. (Ronaldo, Ballivián, 2011) ${ }^{26}$

\section{Reflexión final}

En este trabajo hemos procurado problematizar la relación entre los agronegocios, el extractivismo y los procesos de expulsión de comunidades indígenas del Chaco salteño de sus territorios. En primer lugar, se ha destacado cómo en el lapso de treinta años el avance de la frontera agropecuaria ha modificado drásticamente las condiciones del ambiente natural. Posteriormente, hemos tratado de vincular el avance de la deforestación con datos censales para lograr un análisis comparativo de la situación de la población rural y urbana en cada departamento que conforma el Chaco salteño.

En este caso se pudo ver cómo desde el año 2001 hasta el 2010, momento de agudización de los desmontes, la población indígena de áreas rurales ha tendido a decrecer y, por el contrario, la urbanización ha aumentado en un gran porcentaje. Estos datos revelan que a la par del despojo territorial, las familias que subsistían en el monte se han visto forzadas a migrar a las ciudades en búsqueda de sustento. Desde el punto de vista de los indígenas, pueden inferirse algunas de las causas de tales migraciones. En primer lugar, tanto de los datos censales como de algunos testimonios, se destacan diferentes procesos migratorios rururbanos. Uno corresponde a la contratación de los indígenas como zafreros, vinculados a su labor en los ingenios, periodo que abarcaría desde 1910 hasta 1970. En este caso la contratación de indígenas era temporaria, con lo cual alternaban ciclos de trabajo (cosecha) con ciclos de subsistencia, variando entre el campo 
y los poblados urbanos o en algunos casos estableciéndose en ellos de manera definitiva.

Otro periodo migratorio comienza entre los años 1980 y 1990, cuando se tecnifica la cosecha del azúcar y empiezan nuevas contrataciones en desmontes y actividades agrícolas vinculadas a la producción porotera que contrataba mano de obra indígena temporaria. Tal como puede extraerse de los testimonios, para muchas comunidades este traslado a los poblados cercanos significaba "salir" de la comunidad por primera vez y vincularse al mercado de trabajo y a la vida en el pueblo, donde iban cambiando sus costumbres, lo cual se considera como una alternativa o elección.

Después de los años 2000 aparecen el avance de la producción de soja y la tecnificación de la cosecha de poroto, que va produciendo una exclusión cada vez mayor de los indígenas del mercado laboral y de la subsistencia de la tierra. El periodo más abrupto de deforestación puede establecerse entre los años 2004 y 2007, aunque el proceso no se detuvo hasta el presente, a pesar de las normativas ambientales vigentes.

Los desmontes han provocado un nuevo proceso migratorio del campo a la ciudad, esta vez teniendo como causa principal el hambre y la falta de recursos básicos para la vida, como el agua, los animales y las plantas utilizados como alimento, para usos medicinales y para la producción de artesanías. En este caso, a diferencia de otros periodos migratorios, se trata de traslados forzados por la situación y no de una alternativa de vida.

Respecto a estas últimas migraciones, el hecho de trasladarse a los pueblos o ciudades implica un cambio radical en su forma de vida, y al mismo tiempo una dependencia cada vez mayor de los recursos asistenciales que provee el Estado. Los que prefieren continuar viviendo de lo que queda del monte, lo hacen a costa de muchos padecimientos y como forma de resistir al cambio cultural, aun sabiendo que su vida y la de sus hijos está en riesgo. Este es el porcentaje cada vez menor de población de áreas rurales que mermó significativamente en los últimos quince años.

\section{Referencias}

Adámoli, Jorge, Rubén Ginzburg y Sebastián Torrella. 2011. Escenarios productivos y ambientales del Chaco Argentino: 1977-2010. Buenos Aires: FCEyN-UBA. Consultado el 10 de octubre del 2014. https://www.researchgate.net 
Azcuy Ameghino, Eduardo y Lucía Ortega. 2010. "Sojización y expansión de la frontera agropecuaria en el NEA y NOA: transformaciones, problemas y debates”. Documentos del CIEA 5: 14-159. Consultado el 7 de abril del 2019. http://bibliotecadigital.econ.uba.ar/download/docuciea/docuciea_n5_07.pdf

Bidaseca, Karina. 2014. "Procesamiento y actualización de datos del estudio 'Sistematización de los problemas de tierra de los agricultores familiares. República Argentina' en seis provincias afectadas por el fenómeno del land grabbing”. Documentos de Investigación Social 25. Consultado el 15 de noviembre del 2016. http://www.unsam.edu.ar/institutos/ idaes/docs/DocIS_25_Bidaseca.pdf

Composto, Claudia y Mina Lorena Navarro. 2014. "Claves de lectura para comprender el despojo y las luchas por los bienes comunes naturales en América Latina”. En Territorio en disputa. Despojo capitalista, lucha en defensa de los bienes comunes naturales y alternativas emancipatorias en América Latina, compilado por Claudia Composto y Mina Lorena Navarro, 33-75. Ciudad de México: Bajo Tierra Ediciones.

De Sousa Santos, Boaventura. 1991. "Una cartografía simbólica de las representaciones sociales. Prolegómenos a una concepción posmoderna del derecho”. Nueva Sociedad 116: 18-38.

Domínguez, Diego y Pablo Sabatino. 2008. "La conflictividad en los espacios rurales de Argentina”. Lavboratorio 10 (22): 38-44. https://docplayer.es/79039194-La-conflictividad-enlos-espacios-rurales-de-argentina-1-diego-dominguez-2-y-pablo-sabatino-3.html

Duarte, Matías. 2009. "Marco jurídico: los derechos de los pueblos y comunidades. La situación del dpto. San Martín”. En Los pueblos indígenas de la provincia de Salta. La posesión y el dominio de sus tierras, coordinado por Catalina Buliubasich y Ana González, 35-51. Salta: Cephia.

Escobar, Arturo. 1995. Encountering Development. The Making and Unmaking of The Third World. Nueva Jersey: Princeton University Press.

—. 2005. Más allá del Tercer Mundo. Globalización y diferencia. Bogotá: Instituto Colombiano de Antropología e Historia; Universidad del Cauca.

Flores Klarik, Mónica. 2011. "Etnicidad, política y territorialidad. Conflictos territoriales y procesos organizativos indígenas en la zona de Tartagal-Salta (1995-2010)”. Tesis doctoral en Antropología Social, Facultad de Filosofía y Letras, Universidad de Buenos Aires, Buenos Aires.

Galafassi, Guido. 2008. "Contradicciones sociales y procesos de movilización en espacios rurales de Argentina en las últimas décadas”. En Pasado y presente en el agro argentino, compilado por Javier Balsa, Graciela Mateo y María Silvia Ospital, 181-200. Buenos Aires: Lumiere.

Giarracca, Norma y Miguel Teubal, coords. 2013. Actividades extractivas en expansión. ¿Reprimarización de la economía argentina? Buenos Aires: Antropofagia.

Gordillo, Gastón y Silvia Hirsch, comps. 2010. Movilizaciones indígenas e identidades en disputa en la Argentina. Buenos Aires: La Crujía.

Gudynas, Eduardo. 2009. "Diez tesis urgentes sobre el nuevo extractivismo”. En Extractivismo, política y sociedad, de Jürgen Schuldt, Alberto Acosta, Alberto Barandiarán, Anthony Bebbington, Mauricio Folchi, Alejandra Alayza y Eduardo Gudynas, 187-225. Quito: Centro Andino de Acción Popular (CAAP); Centro Latino Americano de Ecología Social (Claes). https://www.rosalux.org.ec/pdfs/extractivismo.pdf 
Harvey, David. 2004. El nuevo imperialismo. Madrid: Akal.

Leake, Andrés, coord. 2009. Los pueblos indígenas cazadores-recolectores del Chaco salteño. Población, economía y tierras. Salta: Fundación Asociana.

Leake, Andrés, Enrique Omar López y María Cecilia Leake. 2016. La deforestación del Chaco salteño, 2004-2015. Salta: Fundación Refugio; Redaf; SMA Ediciones. http://redaf. org.ar/wp-content/uploads/2017/02/Deforestaci\%C3\%B3n-del-Chaco-salte\%C3\%B1o2004-2015-versi\%C3\%B3n-digital.pdf

Manzanal, Mabel y Federico Villarreal, orgs. 2010. El desarrollo y sus lógicas en disputa en territorios del norte argentino. Buenos Aires: Ciccus.

Merlinsky, Gabriela. 2013. Cartografías del conflicto ambiental en Argentina. Buenos Aires: Ciccus.

Naharro, Norma, Marcela Amalia Álvarez y Mónica Flores Klarik. 2015. “Tensiones entre políticas agrarias y derechos indígenas y ambientales. El caso de los agronegocios en Ballivián”. En Neocolonialismo, capitalismo y resistencias subalternas, editado por Sonia Álvarez Leguizamón, 161-194. Rosario: Prohistoria.

Naharro, Norma, Mónica Flores Klarik y Leda Kantor. 2009. "Situación actual de las comunidades. Análisis cualitativo”. En Los pueblos indígenas de la provincia de Salta. La posesión y el dominio de sus tierras, coordinado por Catalina Buliubasich y Ana González, 35-51. Salta: Cephia.

Rodríguez Garavito, César, coord. 2016. Extractivismo versus derechos humanos. Crónicas de los nuevos campos minados en el sur global. Buenos Aires: Siglo XXI.

Schmidt, Mariana. 2009. "Situación de la tierra en la provincia de Salta. Una aproximación al contexto previo al ordenamiento territorial de bosques nativos”. Estudios Rurales 2 (3): 75-103. http://ppct.caicyt.gov.ar/index.php/estudios-rurales/article/view/1343

Slutsky, Daniel. 2005. "Los conflictos por la tierra en un área de expansión agropecuaria del NOA. La situación de los pequeños productores y los pueblos originarios”. Revista Interdisciplinaria de Estudios Agrarios 23: 59-100.

Svampa, Maristella. 2008. "Argentina: una cartografía de las resistencias (2003-2008). Entre las luchas por la inclusión y las discusiones sobre el modelo de desarrollo”. Observatorio Social de América Latina IX (24): 17-50. Buenos Aires: Clacso.

Svampa, Maristella y Mirta Antonelli, eds. 2009. Minería transnacional, narrativas del desarrollo y resistencias sociales. Buenos Aires: Biblos.

Yudi, Raúl Javier. 2009. "El desarrollo extraviado: historia y números de la expansión de la frontera agropecuaria en el Chaco salteño”. Ponencia presentada en el IV Congreso Argentino y Latinoamericano de Antropología Rural, Mar del Plata, 25-27 de marzo.

Zibechi, Raúl. 2014. "El estado de excepción como paradigma político del extractivismo”. En Territorio en disputa. Despojo capitalista, lucha en defensa de los bienes comunes naturales y alternativas emancipatorias en América Latina, compilado por Claudia Composto y Mina Lorena Navarro, 76-88. Ciudad de México: Bajo Tierra. 